ARCHIVO ESPAÑOL DE ARTE, LXXXIV, 336

OCTUBRE-DICIEMBRE 2011, pp. 379-394

ISSN: 0004-0428

\title{
VARIA
}

\section{LOS DESPOSORIOS MÍSTICOS DE SANTA CATALINA DE ALEJANDRÍA, REAPARICIÓN DE UN LIENZO DE TEMÁTICA INÉDITA EN LA OBRA DE ZURBARÁN}

\author{
Odile Delenda \\ Wildenstein Institute
}

\begin{abstract}
Análisis estilístico e iconográfico de los Desposorios místicos de santa Catalina de Alejandría, lienzo inédito de Francisco de Zurbarán. Esta obra, reaparecida en una colección privada europea, figuraba en el inventario y tasación de los bienes del pintor después de su muerte.

Palabras clave: Desposorios místicos de santa Catalina de Alejandría; Lienzo inédito; Inventario; Francisco de Zurbarán; Antonius II Wierix.
\end{abstract}

\section{THE MYSTIC MARRIAGE OF SAINT CATHERINE OF ALEXANDRIA, THE REAPPEARANCE OF} AN UNPUBLISHED PAINTING BY ZURBARAN

The author presents a stylistic and iconographic analysis of The Mystic Marriage of Saint Catherine of Alexandria, a previously unpublished canvas by Francisco de Zurbarán. This painting, recently reappeared in a European private collection, was listed in a post-mortem inventory and valuation of the deceased artist's works.

Key words: The Mystic Marriage of Saint Catherine of Alexandria; Unpublished painting; Inventory; Francisco de Zurbarán; Antonius II Wierix.

Fallecido en Madrid el 27 de agosto de 1664, Francisco de Zurbarán había redactado la víspera su testamento ${ }^{1}$, expresando su deseo de ser enterrado en el convento de los Agustinos Descalzos, actualmente desaparecido. No dejaba deudas y el inventario de sus bienes, establecido por el escribano Roque Antonio de Palacio el 3 de septiembre de 1664 y dado a conocer por M.L. Caturla $^{2}$, demuestra que su hogar no tenía nada que envidiar a los de personajes de un cierto rango social. Sus bienes podían ser los de un artesano acomodado, con algunos muebles de gran

\footnotetext{
${ }^{1}$ Documento descubierto y publicado por CAturla, María Luisa, "Fin y muerte de Francisco de Zurbarán”, Documentos recogidos y comentados por María Luisa Caturla. Ofrecidos en la conmemoración del III centenario. Editados por la Dirección general de Bellas Artes, Ministerio de Educación y Ciencia, Madrid, 1964, pp. 16-19 y CATURLA, María Luisa, Francisco de Zurbarán. Traducción, adaptación y aparato crítico de DelendA, Odile, París, 1994, Documento n. ${ }^{\circ} 203$, p. 324.

2 Caturla, op. cit., pp. 19-23 y Caturla-Delenda, op. cit., Documento n. ${ }^{\circ}$ 205, pp. 324-325.
} 
valor en una época en que eran todavía escasos. En el inventario se citan varios cuadros, lienzos preparados para pintar y una gran cantidad de estampas, que le servían frecuentemente para componer sus obras. Entre las pinturas de Zurbarán que permanecieron en su obrador madrileño tras su muerte se encontraba: "Otra [hechura] nra Señora y el niño y Santa Catalina con mar$c o$ "3. Un año después de la muerte del pintor, su tercera esposa y viuda doña Leonor de Tordera, pidió que se hiciera la valoración de los bienes de su marido en su casa y obrador madrileños. En la tasación de las pinturas, llevada a cabo en Madrid el 12 de agosto de 1665 por el maestro pintor Luis Jiménez, encontramos de nuevo esta misma pintura citada: "Un lienço de bara y quartta de Nuestra Señora y Santta Catalina con moldura en cien RS...V100" $n a$ actualmente desconocida, los temas de los otros lienzos conservados fueron tratados repetidas veces por el maestro extremeño y son difíciles de localizar. No es el caso de los Desposorios místicos de santa Catalina de Alejandría de los cuales no conocíamos ninguna versión hasta fechas recientes: acaba de reaparecer en una colección privada ${ }^{5}$ (fig. 1), un lienzo que bien podría ser el que figura en el inventario y en la tasación de los bienes del pintor.

La pintura tardía de Zurbarán ha sido menospreciada antaño por los historiadores. Sin embargo, una treintena de cuadros, a menudo firmados y fechados, dan testimonio de la última época del maestro en Madrid (1658-1664). Este período poco estudiado e incluso desvalorizado anteriormente, ha vuelto a ser apreciado en los últimos años gracias, sobre todo, a la memorable exposición Zurbarán, la obra final, organizada por Alfonso Pérez Sánchez en Bilbao en el año $2000^{6}$. Es cierto que parte de la producción final del artista ha desaparecido hoy en día, pero con suerte puede reaparecer: las vicisitudes de las guerras y la secularización de los bienes eclesiásticos han arruinado particularmente la conservación de estos cuadros, esencialmente religiosos. No obstante, se conservan suficientes lienzos de este último período para distinguir claramente su originalidad en la evolución pictórica de Zurbarán.

La estancia del viejo maestro en Madrid está bien documentada. El 23 de diciembre de 1658, Francisco de Zurbarán testifica en Madrid a favor de su amigo Diego de Silva Velázquez, "que conoce [...] quarenta años ha"7. Esta disposición amistosa a favor de Velázquez, cuando se investigaban minuciosamente los antecedentes del pintor de Felipe IV para su admisión en la Orden de Santiago como consagración final de una brillante carrera, ofrece una interesante información sobre los últimos años de la vida de Zurbarán. Valioso testimonio de la amistad juvenil de dos de los pintores más dotados de su generación, ahora en el otoño de su vida, este documento proporciona además la fecha de llegada a Madrid del pintor extremeño a finales de mayo de 1658. Se han discutido mucho las razones de este establecimiento final en la Corte, pero la hipótesis de Enrique Valdivieso parece la más verosímil:

"En 1658, no a buscar el trabajo que faltaba en Sevilla ni tampoco pobre y arruinado como se venía señalando, Zurbarán se traslada a Madrid, seguramente con la pretensión de alcanzar allí el título de pintor de cámara. Tampoco es probable que Zurbarán se marchase de Sevilla ante la creciente popularidad de Murillo y su consiguiente pérdida

\footnotetext{
3 Archivo Histórico de Protocolos, Madrid, Protocolo 10592, folio 451 (CATURla, op. cit., p. 16 y CATURLA-DeLENDA, op. cit., p. 324).

${ }^{4}$ Ibidem, folio 453 (Caturla, op. cit., p. 20 y Caturla-Delenda, op. cit., pp. 324-325).

5 Desposorios místicos de santa Catalina de Alejandría, óleo sobre lienzo, $121 \times 102,7 \mathrm{~cm}$., restaurado recientemente por Robert Shepherds Ltd, Europa, colección privada.

${ }^{6}$ Zurbarán, la obra final, 1650-1664, Museo de Bellas Artes de Bilbao, 10 de octubre de 2000-14 de enero de 2001.

7 Cruzada Villaamil, Gregorio, Revista de Europa, II, 1874, pp. 106-107 y Varia Velazqueña, Madrid, 1960. II, Documentos, pp. 329-330 (CATURLA-Delenda, op. cit., Documento n. ${ }^{\circ} 183$, p. 320).
} 


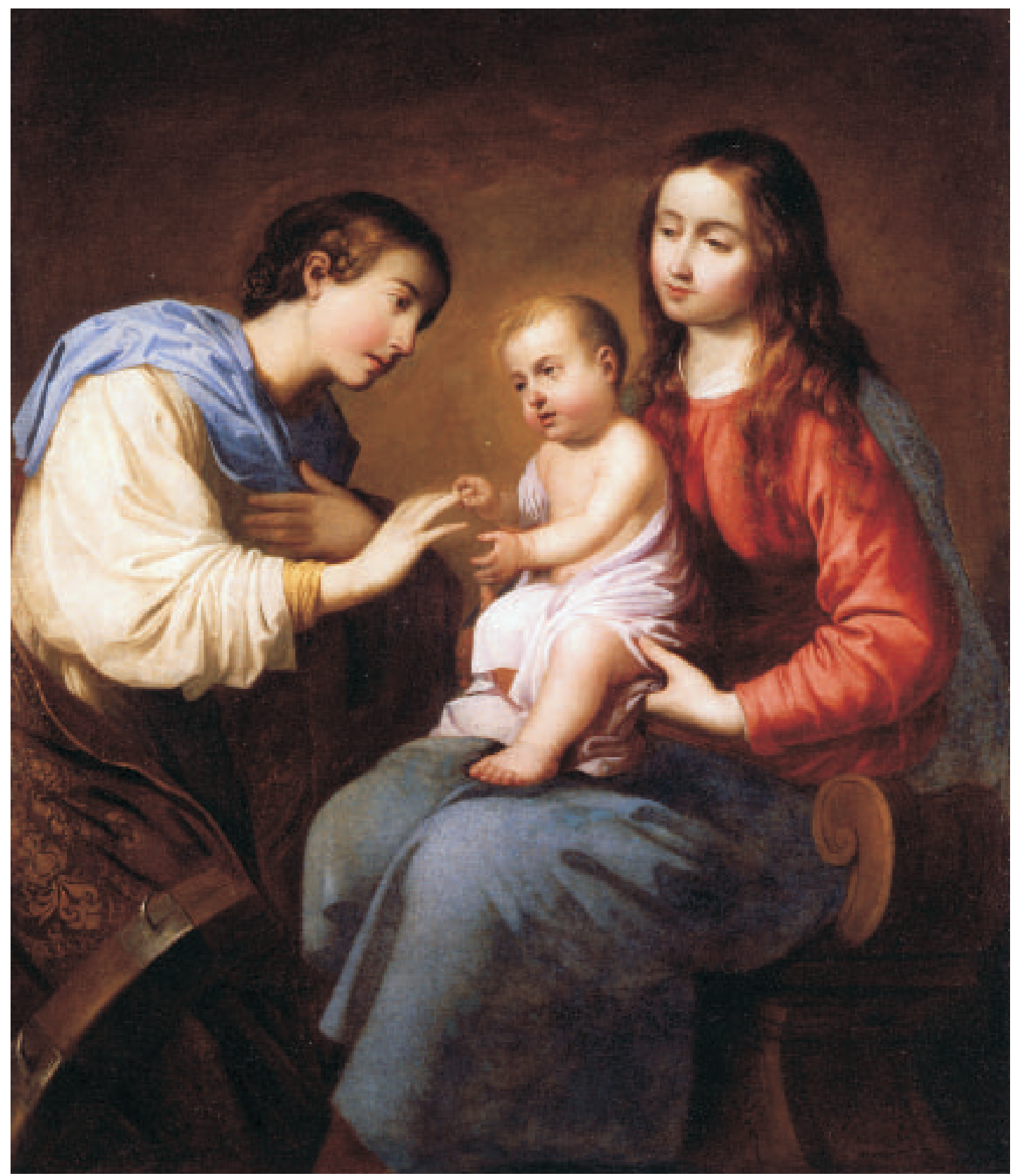

Fig. 1. Francisco de Zurbarán, Desposorios místicos de santa Catalina de Alejandría, óleo sobre lienzo, $121 \times 102,7$ cm., 1660-1662, Europa, colección privada. CArchivo Wildenstein Institute, París.

Arch. esp. arte, LXXXIV, 336, oCTUBRE-DICIEMBRE 2011, 379-394, ISSN: 0004-0428 
de clientela, sino el deseo de culminar su carrera artística con la obtención del más alto grado a que un pintor español podía aspirar. Su subsistencia en la Corte quedaba garantizada con las rentas de las numerosas casas que Zurbarán poseía en Sevilla, y los trabajos pictóricos que iba realizando en Madrid. Sus esperanzas de triunfar allí estaban basadas probablemente en el apoyo que Velázquez pudiera prestarle, en base de su antigua amistad"8.

Los últimos años del pintor extremeño en Madrid nos resultan actualmente bastante bien conocidos. Su instalación, primero provisional (en su testimonio el pintor declara ser todavía "habitante de Sevilla, residente en Madrid") parece ser definitiva a partir del 24 de junio de 1659. En esta fecha el maestro otorga conjuntamente con su mujer doña Leonor de Tordera -ambos residentes en Madrid "calle de las Carretas, parroquia de Santa Cruz"- varios poderes a amigos o parientes sevillanos para resolver definitivamente sus asuntos en la capital andaluza, en particular ciertas transacciones inmobiliarias complejas ${ }^{9}$. Cuando el pintor extremeño se instala en Madrid, el riguroso tenebrismo de la primera mitad del Siglo de Oro español había evolucionado en los años cuarenta hacia una pintura más clara, menos severa, conforme al nuevo gusto de una clientela erudita y cultivada. Los pintores iban abandonando el estilo austero impuesto por la reforma católica de principios del siglo. Más que ninguno, Zurbarán se había conformado a dicho estilo, pero él también paulatinamente iba renovándolo. La nueva generación de artistas plenamente barrocos, como Carreño de Miranda (1614-1685), Francisco Rizi (1614-1685) o Francisco de Herrera "el Mozo" (1627-1685) comenzaba a imponer una profunda transformación dentro de la escuela madrileña, con una pintura más clara y con formas dinámicas e ilusionistas para decorar grandes espacios. Este nuevo estilo aparece completamente opuesto al genio estable y poderoso de Francisco de Zurbarán y para él no tenía ningún sentido competir con los maestros decoradores de Madrid. Animado sin duda por esas nuevas creaciones, pero también por el contacto con las pinturas italianas y flamencas de las colecciones reales que descubriría en la Corte, el pintor extremeño supo expresar entonces su personalidad profunda, adecuando su estilo hacia una manera más suave y refinada, muy diferente al barroco del entorno madrileño pero que confirma sus dotes de colorista y de creador.

A excepción de los cuadros dispersos del convento franciscano de San Diego de Alcalá de Henares, no parece que Zurbarán haya participado en otros grandes ciclos pictóricos. Durante estos años se vio obligado a trabajar sin la colaboración de sus ayudantes en obras esmeradas para una clientela privada, a menudo aristocrática y sin duda conocida por el pintor desde hacía mucho tiempo. Dicha clientela deseaba adquirir obras de calidad que, al mismo tiempo, favorecieran la devoción. El éxito de ciertos temas explica su repetición: Paños de la Verónica, Inmaculadas, Sagradas Familias y varios santos franciscanos, de los que realiza múltiples versiones. De 1658 son varias pinturas de formato medio realizadas con gran esmero, como para afirmar su talento ante estos clientes: el espléndido cuadro de la Virgen y el Niño Jesús con San Juan niño (San Diego Museum of Art) ${ }^{10}$, la Virgen de la leche (Moscú, Museo Pushkin) ${ }^{11}$, así como una emocionante Verónica (Valladolid, Museo Nacional de Escultura) ${ }^{12}$, especie de "trompe-1'œil a la divino". Dos Inmaculadas de una iconografía original (Dublín, National Gallery y Madrid,

\footnotetext{
8 VAldivieso, Enrique, Historia de la pintura sevillana, Sevilla, 1986, ed. 2002, p. 176.

9 KinKeAD, Duncan T., "The Last Sevillian Period of Francisco de Zurbarán", The Art Bulletin, LXV, 1983, pp. 305-311 (Caturla-Delenda, op. cit., Documentos n. ${ }^{\text {os }}$ 186-188, pp. 320-321).

${ }^{10}$ Delenda, Odile, Francisco de Zurbarán, 1598-1664. Catálogo razonado y crítico. Volumen I, Madrid, 2009, n. ${ }^{\circ} 255$.

${ }^{11}$ Idem, n. ${ }^{\circ} 252$.

${ }^{12}$ Idem, n. 251.
} 
Oviedo, colección Masaveu) ${ }^{13}$, igualmente fechadas en 1658, testimonian su deseo evidente de renovar este tema tan frecuente en el siglo de Oro español. Existen otros cuadros firmados y fechados en 1659, como el Descanso en la huida a Egipto (Budapest, Szépmüvészeti Múseum) ${ }^{14}$, la Virgen y el Niño dormido (Madrid, colección particular) ${ }^{15}$, San Francisco "Hamlet" (Madrid, colección Arango) ${ }^{16}$, su pareja San Francisco de Paula (Canarias, colección particular) ${ }^{17}$ y un San Pedro arrepentido (Puebla, Méjico, Museo José Luis Bello) ${ }^{18}$. Otros están fechados en 1661, como el Cristo recogiendo sus vestiduras después de la flagelación (Jadraque, iglesia parroquial) $^{19}$, las dos preciosas Inmaculadas Niñas (Budapest, Szépmüveszeti Múseum y Langon, iglesia parroquial) ${ }^{20}$ y una impresionante Aparición de la Virgen con el Niño a San Francisco en la Porciúncula (Illingen-Wustweiler Alemania, Capilla Statio Dominus Mundi) ${ }^{21}$. Su última obra, firmada y fechada en 1662, es la Virgen con el Niño Jesús y San Juan niño (Bilbao, Museo de Bellas Artes) ${ }^{22}$. La mayoría de estas obras, totalmente autógrafas, parece destinada a oratorios privados, pero se desconoce la identidad de sus comitentes. Como hemos dicho, a partir de 1650, contrariamente a lo que se ha afirmado en repetidas ocasiones, el talento de Zurbarán no disminuye, sino que evoluciona. Abandona el tenebrismo pronunciado de sus primeros años, sustituyéndolo por una paleta más suave y un estilo vaporoso más cercano a los modelos boloñeses y al gusto de su nueva clientela que a la obra del joven Murillo, estrella ascendente de la escuela sevillana, como se sigue repitiendo desde hace décadas.

Se desconoce la procedencia del lienzo de los Desposorios místicos de Santa Catalina de Alejandría que hemos podido examinar recientemente. Sólo sabemos que se conservaba en Francia desde aproximadamente los años ochenta del siglo XX. Su formato mediano conviene perfectamente para un cuadro de devoción privada. Si se trata, como suponemos, del lienzo que se encontraba en el obrador madrileño de Zurbarán tras su muerte, no sería un encargo de algún comitente sino una obra de temática muy popular entonces destinada a la venta directa.

En la imagen que nos ocupa, la tonalidad de la escena milagrosa se hace íntima y recogida de acuerdo con la sensibilidad de tipo devocional que el viejo pintor manifiesta en las pinturas de su último período madrileño. La Virgen María, sentada de tres cuartos hacia la izquierda en una silla de caderas en madera taraceada, sostiene al Niño Jesús quien está poniendo una sortija en el dedo anular de una exquisita y refinada joven, inclinada de perfil hacia la madre y su hijo. Por la rueda rota erizada de púas aceradas de metal brillante, pintada con esmero, se reconoce fácilmente a santa Catalina de Alejandría ${ }^{23}$. La joven María tiene unos rasgos de una belleza clásica, rostro ovalado y largos cabellos ondulantes de color moreno con reflejos dorados. Como de costumbre en las obras de Zurbarán, aparece pensativa, con los ojos pudorosamente entornados y esta "mirada interior" tan típica del maestro extremeño. Viste el manto azul y la túnica roja de las numerosas representaciones marianas tardías y un fino lino blanco transparente rodea su cuello. Santa Catalina se presenta de perfil con el pelo del mismo color que él de la Virgen, pero recogido en un elegante y complicado moño sobre la nuca. Lleva un traje aristocrático que corresponde a su condición

13 Idem, n. ${ }^{\text {os }} 253-254$.

${ }^{14}$ Idem, n. ${ }^{\circ} 266$.

${ }^{15}$ Idem, n. ${ }^{\circ} 265$.

${ }^{16}$ Idem, n. ${ }^{\circ} 267$.

${ }^{17}$ Idem, n. ${ }^{\circ} 268$.

18 Idem, n. ${ }^{\circ} 269$.

19 Idem, n. ${ }^{\circ} 282$.

${ }^{20}$ Idem, n. ${ }^{\text {os }} 284-285$.

${ }^{21}$ Idem, n. ${ }^{\circ} 283$.

22 Idem, n. ${ }^{\circ} 286$.

${ }^{23}$ Cuando todo estaba dispuesto para ser sometida al tormento de las ruedas dentadas, un ángel bajado del cielo despedazó el instrumento de su martirio que se convirtió en su atributo más conocido. 
de princesa. Su vestido blanco marfileño, símbolo de su pureza, deja aparecer en los hombros y los puños una camisa de tela fina de un refinado color amarillento. Su cuello está ceñido con un bonito chal de seda de un color azul más claro que el manto de María y bajo la cintura aparece recogida por delante una capa de un suntuoso paño brocado marrón. El Niño Jesús de pelo rubio, chiquillo regordete copiado de un modelo vivo, se hermana con los de estas numerosas Sagradas Familias del período final y se asemeja muchísimo al de la Porciúncula de 1661 (fig. 2). Los pañales, o la sábana, que cubre el cuerpecito desnudo de Jesús, son de un blanco luminoso con delicados dobleces de un color malva muy pálido. Unos arrepentimientos aparecen visibles en las manos y los brazos de la santa y del Niño. La factura delicada y los coloridos luminosos son absolutamente zurbaranescos. La atmósfera del cuadro, tierna y poética, es típica de las últimas obras del artista, hacia 1660-1662.

En cuanto a su composición no debe excluirse la posible influencia de unos grabados de los Wierix del

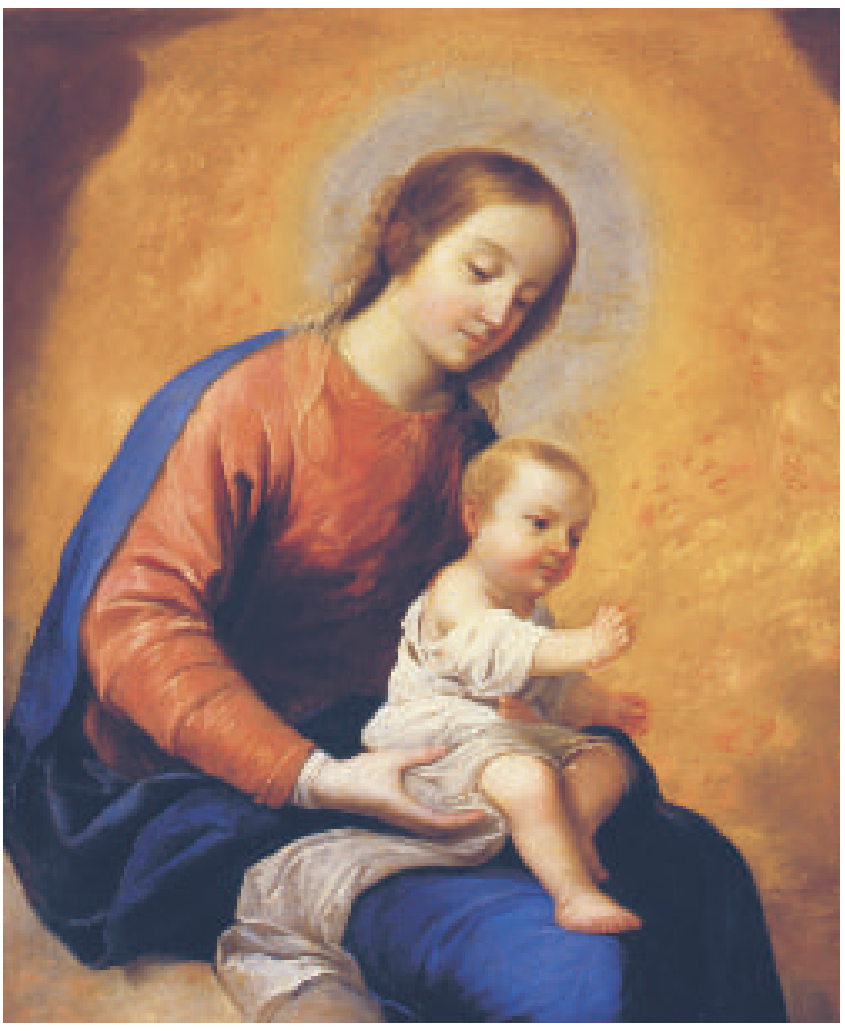

Fig. 2. Francisco de Zurbarán, Aparición de la Virgen con el Niño a San Francisco en la Porciúncula, 202,5 × 158,5 cm, firmado y fechado en 1661, Illingen-Wustweiler Alemania, Capilla Statio Dominus Mundi (detalle del Niño). C)Archivo Wildenstein Institute, París. mismo tema (figs. 3 y 4). Sin embargo el pintor sólo utiliza como modelo la posición de los protagonistas de la escena, eliminando el escenario y los personajes celestes. En la pintura, la Virgen no se presenta inclinada con el Niño como en las estampas flamencas, sino perfectamente derecha, con el rostro grave, meditativo y un poco altivo. Así la postura más majestuosa que Zurbarán da a María conviene mejor al sentimiento de reverencia que tenían que experimentar los fieles según las indicaciones de los exegetas de la reforma católica postridentina. Llama la atención observar como el maestro extremeño despoja a la fuente grabada de los detalles inútiles, insuflando un realismo muy personal y al mismo tiempo una gran poesía al lienzo. Las figuras inmóviles, de tamaño casi natural -lo que les confiere cierta monumentalidad-, emergen sobre un fondo neutro marrón penumbroso, apenas esclarecido por un sutil halo entorno a las cabezas de los protagonistas carentes de aureolas.

La única referencia conocida a un cuadro de esta temática por Zurbarán la encontramos a mediados del siglo XIX cuando Amador de los Ríos describe en la famosa colección de Aniceto Bravo en Sevilla unos Desposorios de Santa Catalina (sin precisar si se trata de Santa Catalina de Siena o Santa Catalina de Alejandría). Por la descripción del estilo de esta pintura se entiende que es una obra tardía que podría coincidir con la que estudiamos ahora:

"Es también del tiempo en que Zurbarán había hecho una transformación en sus tintas, abandonando la aridez de su colorido primitivo. Las figuras están dibujadas con aquella 




Fig. 3. Antonius II Wierix, Desposorios místicos de santa Catalina de Alejandría, grabado, anterior a 1604. (C)Archivo Wildenstein Institute, París.

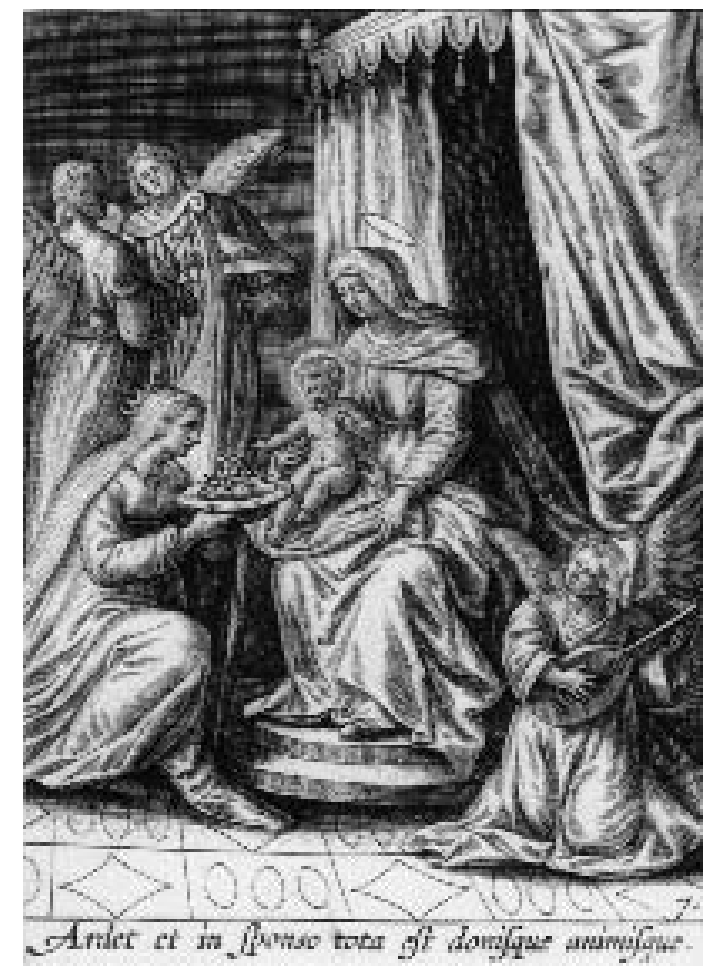

Fig. 4. Antonius III Wierix, Desposorios místicos de santa Catalina de Alejandría, en Vita S. /Catharince virginis/ et martyris, serie de 20 grabados, Amberes, anterior a 1624.

CArchivo Wildenstein Institute, París.

presision [sic] que tanto distingue al discípulo de Roelas y en los ropajes hay flexibilidad sin ecsageración [sic], observándose el partido de pliegues perfectamente desempeñado. En lontananza se ve un hermoso país" ${ }^{24}$.

Esta última frase no corresponde con este cuadro ni con los Desposorios místicos de Santa Catalina de Siena del Meadows Museum de Dallas ${ }^{25}$ (fig. 5). El lienzo de Dallas no puede ser el que aparece en el inventario de Zurbarán, donde se estipula que figuran Nuestra Señora y el Niño, porque por los propios relatos de la santa de Siena sabemos que en la visión mística que tuvo la terciaria dominica desposándose con el Señor, fue Jesús adulto quien le colocó el anillo en el dedo. Catalina de Benincasa (1347-1380), terciaria dominica (llamada entonces mantellata) canonizada en 1461, experimentó numerosas visiones, éxtasis y experiencias místicas bien infor-

24 Amador de los Ríos, José, Sevilla pintoresca o descripción de sus más célebres monumentos artísticos, Sevilla, 1844; reedición facsímil 1979, p. 422.

${ }^{25}$ Delenda 2009, op. cit., n. ${ }^{\circ} 200$. 


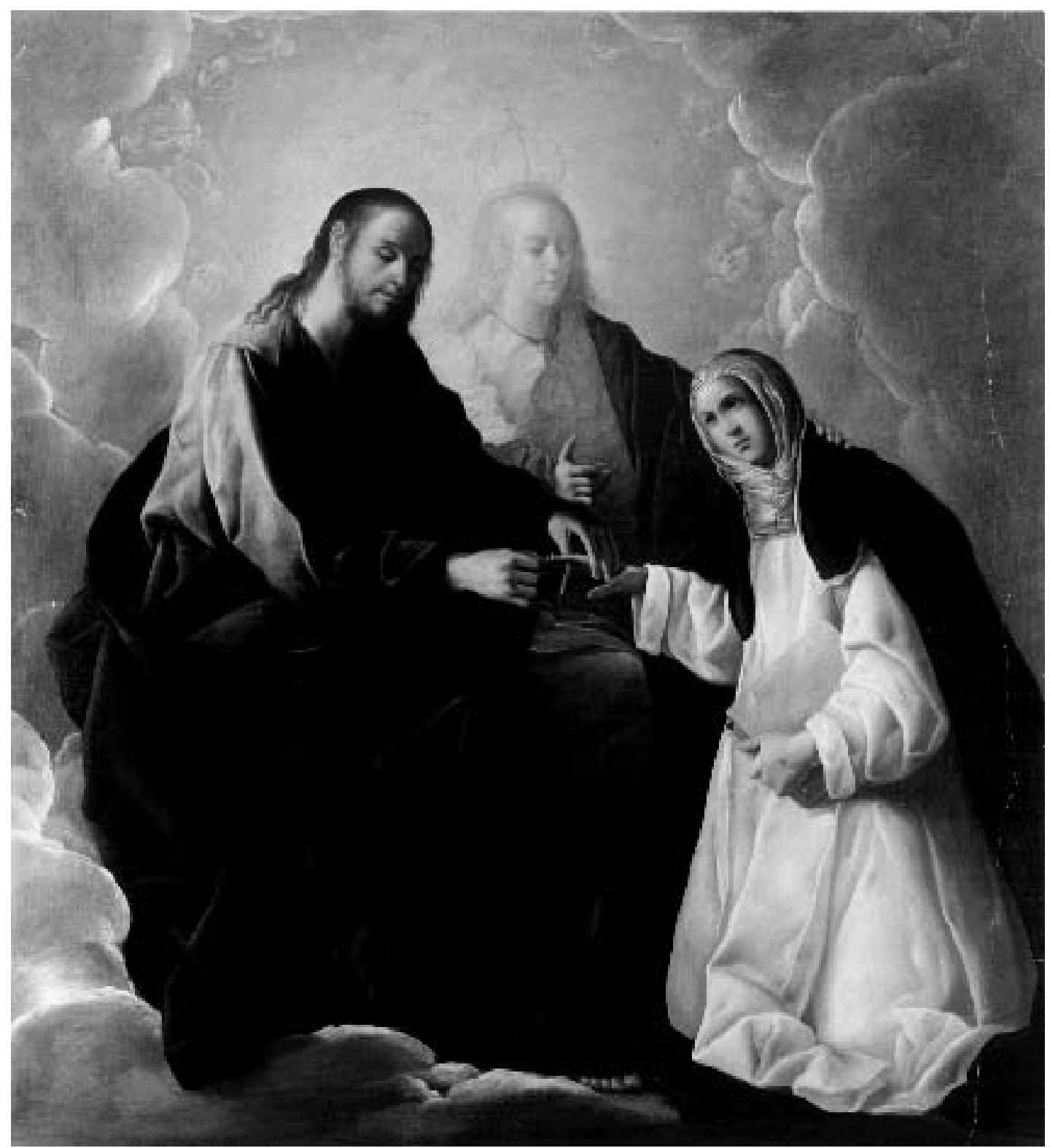

Fig. 5. Francisco de Zurbarán, Desposorios místicos de santa Catalina de Siena, óleo sobre lienzo, $109 \times 100 \mathrm{~cm}$, ca 1645, Dallas, Meadows Museum. CArchivo Wildenstein Institute, París.

madas que relató a su confesor y primer biógrafo Raimundo de Capua ${ }^{26}$. Según este testimonio

${ }^{26}$ La Legenda maior, redactada en latín entre 1385 y 1395 (edición consultada, Raimundo da Capua, Santa Caterina da Siena, Legenda Maior, Siena 1998). Véase FAwTIER Robert, Sainte Catherine de Sienne. Essai de critique des Sources, Vol. I, París 1921, Vol. II, París 1930 y catálogo de la exposición Catherine de Sienne, Aviñón, Grande Chapelle du Palais des Papes, 1992, pp. 25-42. 
directo, sus bodas espirituales con Cristo ocurrieron durante el carnaval de $1366^{27}$. Poco tiempo tras su muerte, santa Catalina de Siena encarnó el perfecto modelo de la santidad moderna. El obispo Pedro de Natalibus fue uno de los escritores casi contemporáneos de la santa dominica que narraron su vida. La Iglesia siempre ha estimado mucho la lectura de la vida de los santos así como la representación de sus hechos, pues en ellos los fieles cristianos encuentran ejemplo y estímulo en el seguimiento de Cristo. Por eso, ya en el siglo VIII, el Oficio Divino incluye la lectura de las Pasiones de los santos. Pero muchas veces, como en el caso precisamente de santa Catalina de Alejandría, por falta de conocimientos exactos o de sentido crítico, tales lecturas se hallaban más próximas a la leyenda que a la historia. Los relatos eran en muchos casos, ingenuos relatos de las vidas de los santos, obras de pedagogía puesta al servicio de la acción divina. En todas las reformas del Oficio Divino se procuró, aunque con poco éxito, mejorar la calidad de estas lecturas. Sin embargo, la hagiografía no tiene los mismos objetivos que una biografía histórica. Para la primera, los "hechos" se encuentran a la disposición de una verdad que se construye de forma edificante: la hagiografía no se refiere a "lo que paso" como la historia, sino a "lo que es ejemplar", en base a una combinación atrayente de virtudes y milagros. Los compiladores de las vidas de los santos copiaban los textos precedentes, o los modificaban, dando preferencia al elemento portentoso.

Santa Catalina de Alejandría, mártir en Egipto en el siglo IV, fue muy célebre desde antiguo y las imágenes de varios episodios de su vida y muerte abundan. Sin embargo, según opinión generalizada entre los hagiógrafos, la historia de esta santa, contrariamente a la de la santa dominica, no tiene ningún apoyo documenta ${ }^{28}$. Los hechos más famosos y reproducidos de su vida fueron recopilados en la Legenda Sanctorum ("Lecturas sobre los Santos"), del dominico Santiago (o Jacobo) de la Vorágine (ca. 1230-1298), arzobispo de Génova, a mediados del siglo XIII: es decir, la celebérrima Leyenda Dorada o urea $^{29}$, manual de referencia obligatoria para los fieles de la época y que tuvo tanta influencia sobre los artistas medievales. Los Desposorios místicos de Santa Catalina con el Niño Jesús es quizás el tema más difundido de la leyenda de esta santa, aunque muy tardío, pues sólo aparece en la hagiografía y en el arte a mediados del siglo XIV. En la pintura renacentista y barroca, el tema constituye un argumento muy atractivo, de carácter alusivo y contemplativo. Catalina de Alejandría no fue mística y se añadió este episodio, por puro interés hagiográfico. Lo veremos en otros relatos de vidas de santas "históricas", como Catalina de Siena o más tarde Teresa de Jesús. La variedad de versiones de los Desposorios de Santa Catalina de Alejandría en el arte es inmensa y probablemente sea el tema más representado en la pintura después de los temas marianos.

En la época de Zurbarán ya no se usaba la Leyenda Dorada como base de inspiración, mientras que el Flos Sanctorum del jesuita Ribadeneyra alcanzaba un enorme éxito popular ${ }^{30}$, siendo una fuente muy manejada por los pintores del siglo de Oro. En el capítulo de la Vida de Santa Cathalina, Virgen y Martyr, Ribadeneyra explica la introducción de este nuevo episodio en la leyenda de la santa mártir:

\footnotetext{
27 Legenda maior, edición 1998, n. 115.

28 Véase Donnini Mauricio, en el Diccionario de los santos, dirigido por LeONARDI Claudio, RiCARDI Andrea y ZARRI, Gabriela, dos volúmenes, Madrid, 2000 (Vol. I, pp. 447-448). Para los relatos latines medievales de la vida de santa Catalina de Alejandría consultar Vitce Sanctce Katarince (Corpus Christianorum, Continuatio Medicevalis, 119119.a), 2 vols., ed. ORBAN A.P., Turnhout, 1992.

${ }^{29}$ De la Vorágine, Santiago, La leyenda dorada. Traducción de Macías, José Manuel, Madrid 1982, Vol. I-II, pp. 765-774.

${ }^{30}$ Ribadeneyra, Fray Pedro de, Flos Sanctorum o libro de las vidas de los Santos, primera parte, Madrid 1599, segunda parte, Madrid 1601, tercera parte, Madrid 1604.
} 
"El obispo Equilino ${ }^{31}$ dice que antes que se bautizasse tuvo un sueño, y revelación, en que se le apareció la Sagrada Virgen María, nuestra Señora, con su precioso Hijo, Niño de extremada belleza, en los brazos, y que la Madre le ofrecia à su Hijo, y el bendito Niño la desechaba, y se extrañaba de ella, diciendo, que en sus ojos no era hermosa aquella doncella, porque no era bautizada. Desperto Cathalina; y entendiendo lo que le faltaba, y que no era digna de vér el hermoso rostro de Jesu-Christo, se hizo Christiana y se bautizo. Tornóle a aparecer Christo de la manera que primero, y regalandola, y haciendo grandes favores en presencia de su Sacratissima Madre, y de muchos Angeles, y Santos del Cielo, se desposo con ella, y le dio el Anillo, como à verdadero Esposo suyo. Despertò de su sueño la gloriosa Virgen, y hallo un Anillo en su dedo. Todo esto refiere este Autor"32.

Cabe preguntarse por qué aparece esta nueva temática a finales del siglo XIV bajo la pluma de Pedro de Natalibus, obispo de Equilo, y por qué tuvo tanto éxito en la época de Zurbarán. Nos parece que podría relacionarse con el espíritu reformista de la Devotio moderna y, por otra parte, con la evolución del ritual de consagración de las vírgenes (Ordo Consecrationis Virginum), o ceremonia de la profesión perpetua de las monjas. Respondiendo a las necesidades de reforma, se extendió por toda Europa, partiendo de los Países Bajos, un movimiento, después denominado Devotio moderna, que constituyó el vehículo de renovación de la vida de los laicos y también de las órdenes religiosas y monásticas, así como la inclusión de nuevas formas de apostolado. Su base era la contemplación y la unión con Dios, a través del conocimiento de las Escrituras, la oración y la iluminación divina, indiferente del estado clerical o laico, insistiendo en el diálogo con Cristo, un Dios próximo, más que en el conocimiento escolástico de su esencia. Jan van Ruysbroeck (Ruysbroeck, c. 1293-1381), "el Admirable", inspirador y promotor de la Devotio moderna en los Países Bajos, escribió su obra maestra, De ornatu spiritualium nuptiarum (Los esponsales espirituales), cuyo influjo fue inmediato y duradero. En realidad, el origen de este lenguaje del místico desposorio arranca del Cantar de los Cantares, el libro de la Biblia preferido de los místicos y fuente de su inspiración.

En los tiempos apostólicos y en los primeros siglos de la Iglesia, las vírgenes cristianas como santa Catalina de Alejandría que querían seguir a Cristo con el corazón indiviso, permanecían en sus casas con sus familias, llevando una vida de oración al servicio de la Iglesia, especialmente mediante el ejercicio de las obras de misericordia. La costumbre existente ya en la Iglesia primitiva de consagrar vírgenes, dio origen a la elaboración de un rito solemne, por el cual la virgen se convertía en una persona consagrada, signo trascendente del amor de la Iglesia a Cristo, imagen escatológica de la Esposa celestial y de la Vida futura. Este rito tiene una historia amplia y compleja hasta su fijación en el pontifical oficial de Roma (siglos XVI-XX) ${ }^{33}$. A finales del siglo XIII, entre los años 1292 y 1296, Guillermo Durando, obispo de Mende, compiló para uso personal un pontifical que llegaría a convertirse en libro oficial de la Iglesia romana. Durando, profesor de derecho canónico durante muchos años en Bolonia y experto liturgista, estaba particularmente preparado para la composición de tal libro litúrgico. Amplió los ritos existentes desde el siglo $\mathrm{X}$ de la entrega de las insignias monásticas y esponsales: el velo, el anillo y la corona, devolviendo al rito de consagración de las vírgenes un marcado sentido matrimonial y desarrollando mucho la ceremonia de su presentación ante el obispo que repre-

\footnotetext{
31 Es decir Pedro de Natalibus (muerto entre 1400 y 1406), obispo de Equilio (Jesolo) y autor de un famoso Martyrologium.

32 Ribadeneyra, op. cit., edición Madrid, 1761, III, p. 524.

33 Véase Metz René, La Consécration des vierges dans l'Église romaine. Étude d'histoire de la liturgie, Estrasburgo, 1954.
} 
senta al esposo, sponsus, Cristo, y las vírgenes, sponsœe, esposas. Así restableció algunas fórmulas de los antiguos pontificales y creó otras, subrayando en todas ellas el sentido del desposorio místico de las vírgenes con Cristo. A partir de este pontifical, durante la ceremonia, el obispo coloca un anillo en el cuarto dedo de la mano izquierda de la virgen consagrada en memoria de su Esposo celestial.

Para contrarrestar la Reforma protestante impulsada por Martín Lutero (y más tarde Calvino) y los enormes problemas que esta le causo, la Iglesia católica se decidió a iniciar también su ansiada reforma, conocida como Contrarreforma o mejor dicho la Reforma católica. Lo que la Iglesia pretendía era frenar los abusos cometidos por el clero y una mejor definición del dogma. Después del Concilio de Trento finalizado en diciembre de 1563 con la promulgación del "decreto de las santas imágenes", los artistas recibieron de los exegetas de la Iglesia unas normas concretas con el fin de adoctrinar y enseñar al pueblo los grandes temas de la doctrina católica. Con estas directrices se perseguía inculcar la piedad en los fieles y al mismo tiempo responder a los errores del protestantismo ${ }^{34}$. En un panfleto, el reformador Martín Lutero explicó por qué las vírgenes podían abandonar sus conventos con la aprobación de Dios, afirmando que la mujer no fue creada para ser virgen, sino para concebir niños. Por esta razón, aunque el tema de los Desposorios místicos de santa Catalina de Alejandría no tuviera ningún cimiento histórico, la Iglesia favoreció su representación en la pintura postridentina.

34 Véase MÂLE, Emile, L'Art religieux de la fin du XVI siècle, du XVII et du XVIII siècle, París, 1932; reed. París, 1972 y 1984; ed. española, Madrid, 2001.

Arch. esp. arte, LXXXIv, 336, octUBRE-DICIEMBRE 2011, 379-394, ISSN: 0004-0428 